\title{
Picosecond X-ray Absorption Spectroscopy of a Photoinduced Iron(II) Spin Crossover Reaction in Solution
}

\author{
Munira Khalil,,,,$+ \ddagger$ Matthew A. Marcus, ${ }^{\S}$ Amanda L. Smeigh," James K. McCusker," \\ Henry H. W. Chong, ${ }^{\ddagger} \perp$ and Robert W. Schoenlein \\ Department of Chemistry, University of California, Berkeley, California 94720, Materials Sciences Division \\ and Advanced Light Source, Lawrence Berkeley National Laboratory, Berkeley, California 94720, and \\ Department of Chemistry, Michigan State University, East Lansing, Michigan 48824, USA
}

Received: September 5, 2005; In Final Form: October 9, 2005

\begin{abstract}
In this study, we perform steady-state and time-resolved X-ray absorption spectroscopy (XAS) on the iron $\mathrm{K}$-edge of $\left[\mathrm{Fe}\left(\operatorname{tren}(\mathrm{py})_{3}\right)\right]\left(\mathrm{PF}_{6}\right)_{2}$ dissolved in acetonitrile solution. Static XAS measurements on the low-spin parent compound and its high-spin analogue, $\left[\mathrm{Fe}\left(\operatorname{tren}(6-\mathrm{Me}-\mathrm{py})_{3}\right)\right]\left(\mathrm{PF}_{6}\right)_{2}$, reveal distinct spectroscopic signatures for the two spin states in the X-ray absorption near-edge structure (XANES) and in the X-ray absorption fine structure (EXAFS). For the time-resolved studies, $100 \mathrm{fs}, 400 \mathrm{~nm}$ pump pulses initiate a charge-transfer transition in the low-spin complex. The subsequent electronic and geometric changes associated with the formation of the high-spin excited state are probed with $70 \mathrm{ps}, 7.1 \mathrm{keV}$, tunable X-ray pulses derived from the Advanced Light Source (ALS). Modeling of the transient XAS data reveals that the average iron-nitrogen $(\mathrm{Fe}-\mathrm{N})$ bond is lengthened by $0.21 \pm 0.03 \AA$ in the high-spin excited state relative to the ground state within $70 \mathrm{ps}$. This structural modification causes a change in the metal-ligand interactions as reflected by the altered density of states of the unoccupied metal orbitals. Our results constitute the first direct measurements of the dynamic atomic and electronic structural rearrangements occurring during a photoinduced $\mathrm{Fe}^{\mathrm{II}}$ spin crossover reaction in solution via picosecond X-ray absorption spectroscopy.
\end{abstract}

\section{Introduction}

Describing the ultrafast structural dynamics of photochemical processes in liquids remains an important scientific objective, both for understanding fundamental chemical and biological phenomena and for developing new materials and devices. The outcome of a photoinduced reaction is dictated by the transient electronic and molecular configurations of the various excited states and the associated time scales of inter- and intramolecular vibrational relaxation processes occurring in solution. Monitoring these dynamics requires tools sensitive to the details of the electronic and atomic structural rearrangements as the reaction evolves over decades in time. ${ }^{1,2}$ It is with this aim that experimental and theoretical studies of photochemical reactions often strive to find a reduced set of variables or "reaction coordinates" that can succinctly, but accurately, describe the reaction process in its entirety.

In this study, we report on the picosecond structural dynamics accompanying a photoinduced spin crossover (SCO) transition of an iron(II) complex in solution. The term SCO typically refers to the interconversion that can occur between the low- and highspin electronic configurations of certain six-coordinate metal complexes. ${ }^{3}$ Elucidating the microscopic factors that dictate the roles played by different spin states in transition metal complexes is crucial for understanding classic textbook reactions

* To whom correspondence should be addressed. E-mail: munira@berkeley.edu.

$\doteqdot$ University of California.

Materials Science Division, Lawrence Berkeley National Laboratory.

$\S$ Advanced Light Source, Lawrence Berkeley National Laboratory.

"Michigan State University.

${ }^{\perp}$ Present address: Division of Engineering and Applied Sciences, Harvard University, Cambridge, MA 02138. such as racemization, electron transfer, and ligand substitution. ${ }^{4}$ Spin-state equilibria are also considered to be an important component of heme protein biochemistry. ${ }^{5}$ Additionally, compounds exhibiting the SCO effect are being actively pursued for their potential applications in magnetic storage and as the basis of bistable devices. ${ }^{6}$ Since the discovery of spin equilibria in the $1930 \mathrm{~s},{ }^{7,8}$ considerable knowledge has been gained about the physicochemical properties of SCO complexes using various physical methods. ${ }^{4,9,10}$ The kinetics of the SCO transition has been studied using a number of techniques, most notably lasertemperature jump and optical pump-probe spectroscopies. ${ }^{4,11}$ However, the structural dynamics that accompany the change in electronic configuration during the course of the SCO transition have never been directly measured. We approach this problem using ultrafast X-ray absorption spectroscopy to map out the electronic and geometric changes associated with the transition metal center after photoinitiating a SCO reaction.

Transition metal complexes and metalloproteins have long been characterized by X-ray absorption spectroscopy (XAS), ${ }^{12}$ which consists of the XANES (X-ray absorption near edge structure) region around the vicinity of the transition edge $(-20$ to $50 \mathrm{eV}$ relative to the edge energy) and the oscillatory EXAFS (extended X-ray absorption fine structure) region at higher energies (10 to $500 \mathrm{eV}$ above the edge energy). ${ }^{13-15}$ The XANES spectrum arises from electronic transitions of core levels to empty bound states and to the continuum providing information about the local coordination geometry and oxidation state of the X-ray absorbing atom. The EXAFS oscillations result from the interference between the outgoing photoelectron wave from the X-ray absorbing atom and the backscattered photoelectron waves from the neighboring atoms. A Fourier analysis of the EXAFS spectrum reveals the local structure around the 
(a)

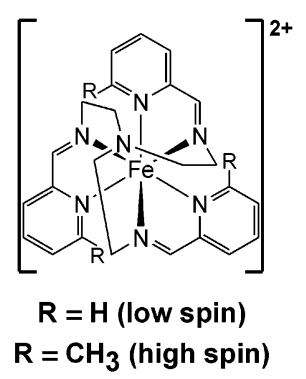

(b)

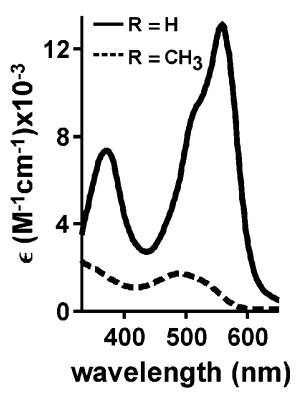

(c)

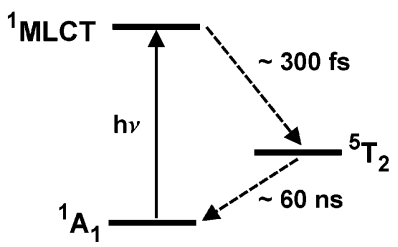

Figure 1. Physical and photochemical properties of the low-spin $\mathrm{Fe}^{\mathrm{II}}$ complex used in the X-ray absorption studies. (a) Multidentate ligand structure of the cation in $\left[\mathrm{Fe}\left(\operatorname{tren}(\mathrm{py})_{3}\right)\right]\left(\mathrm{PF}_{6}\right)_{2}\left(\operatorname{tren}(\mathrm{py})_{3} \equiv \operatorname{tris}((N-(2-\right.$ pyridylmethyl)-2-iminoethyl)amine). This compound has a low-spin $\left({ }^{1} \mathrm{~A}_{1}:\left(t_{2}\right)^{6}(e)^{0}\right)$ ground state. The addition of the methyl groups results in the high-spin $\left({ }^{5} \mathrm{~T}_{2}:\left(t_{2}\right)^{4}(e)^{2}\right)$ compound, [Fe(tren $\left.\left.(6-\mathrm{Me}-\mathrm{py})_{3}\right)\right]\left(\mathrm{PF}_{6}\right)_{2}$. (b) Electronic absorption spectra of the low- (solid line) and high-spin (dashed line) complexes dissolved in acetonitrile at room temperature. The spectrum of the low-spin complex is dominated by ${ }^{1} \mathrm{~A}_{1} \rightarrow{ }^{1} \mathrm{MLCT}$ transitions at 370,520 , and $560 \mathrm{~nm}$, while that of the high-spin complex reveals a much weaker ${ }^{5} \mathrm{~T}_{2} \rightarrow$ MLCT transition at $490 \mathrm{~nm}$ and a ${ }^{5} \mathrm{~T}_{2} \rightarrow$ ${ }^{5} \mathrm{E}$ ligand field transition at $855 \mathrm{~nm}$ (not shown). (c) Simplified depiction of the photoinduced low-spin to high-spin conversion of [Fe(tren $\left.\left.(\text { py })_{3}\right)\right]$ $\left(\mathrm{PF}_{6}\right)_{2}$ following ${ }^{1} \mathrm{~A}_{1} \rightarrow{ }^{1} \mathrm{MLCT}$ excitation as determined by ultrafast transient optical absorption spectroscopy (see ref 37 for further information).

absorbing atom in terms of bond lengths, coordination numbers and local geometry.

XAS of transition metal K-edges has matured into an active area of research in biology, chemistry, and physics following the development of modern synchrotron sources. Besides being sensitive to minute structural and electronic changes around the metal atom, XAS relies on processes occurring on subfemtosecond time scales, making it an ideal tool for studying local time-dependent phenomena accompanying chemical processes in dispersed media. ${ }^{16}$ While this approach has been proposed for some time, it has not been trivial to implement due to experimental difficulties. ${ }^{17-23}$ There exists a need for a tunable source of ultrafast pulsed X-rays with sufficient flux to perform transient experiments with a high signal-to-noise ratio without excessive signal averaging and/or sample damage. ${ }^{24,25}$ Also, to probe a photochemical reaction from start to finish, the delay between the initiating pump pulse and the X-ray probe pulse needs to be scanned over appropriate time scales (i.e. from tens of femtoseconds to nanoseconds). The nascent and growing field of ultrafast XAS has recently been reviewed, and the experimental challenges and recent accomplishments using synchrotron and laboratory based sources are outlined in great detail. ${ }^{26-28}$ At the same time progress is being made in the complementary fields of ultrafast X-ray diffraction to study time evolving structures in crystals and recently in solution. ${ }^{29-32}$

The chemical structures of the $\mathrm{Fe}^{\mathrm{II}}$ complexes used in this study are shown in Figure 1a. An advantage of this system in the present context lies in the ability to control the ground state of the molecule through synthetic means. It is known that replacement of the protons ortho to the pyridyl nitrogens with methyl groups converts the low-spin $\left({ }^{1} \mathrm{~A}_{1}:\left(t_{2}\right)^{6}(e)^{0}\right)$ complex, $\left[\mathrm{Fe}\left(\operatorname{tren}(\mathrm{py})_{3}\right)\right]\left(\mathrm{PF}_{6}\right)_{2}$ to a high-spin $\left({ }^{5} \mathrm{~T}_{2}:\left(t_{2}\right)^{4}(e)^{2}\right)$ analogue, $\left[\mathrm{Fe}\left(\operatorname{tren}(6-\mathrm{Me}-\mathrm{py})_{3}\right)\right]\left(\mathrm{PF}_{6}\right)_{2}{ }^{33} \mathrm{X}$-ray crystallographic studies have confirmed the hexadentate nature of the ligands in both complexes, resulting in a slightly distorted octahedral molecular geometry around the iron atom. ${ }^{34,35}$ The electronic absorption spectrum of the low-spin $\mathrm{Fe}^{\mathrm{II}}$ compound (solid line, Figure 1b) reveals intense metal-to-ligand charge-transfer bands $\left({ }^{1} \mathrm{~A}_{1} \rightarrow\right.$ $\left.{ }^{1} \mathrm{MLCT}\right)$ at 560,520 , and $370 \mathrm{~nm} \cdot{ }^{36}$ It has been shown previously that photoexcitation into the ${ }^{1}$ MLCT bands of the low-spin compound results in the formation of the high-spin ${ }^{5} \mathrm{~T}_{2}$ term as its lowest-energy excited state. The spectroscopic features of this excited state are identical to that of the highspin analogue, $\left[\mathrm{Fe}\left(\operatorname{tren}(6-\mathrm{Me}-\mathrm{py})_{3}\right)\right]\left(\mathrm{PF}_{6}\right)_{2}$. These observations enabled the characterization of the kinetics associated with the photoinduced SCO event using femtosecond transient absorption spectroscopy and the results are summarized in Figure 1c. ${ }^{11,37,38}$

Here we consider the structural changes associated with the ultrafast photoinduced conversion of the ground low-spin ${ }^{1} \mathrm{~A}_{1}$ state to the excited high-spin ${ }^{5} \mathrm{~T}_{2}$ state of $\left[\mathrm{Fe}\left(\operatorname{tren}(\mathrm{py})_{3}\right)\right]\left(\mathrm{PF}_{6}\right)_{2}$ dissolved in acetonitrile solution using synchrotron-based XAS. Time-resolved X-ray absorption spectra of $\left[\mathrm{Fe}\left(\operatorname{tren}(\mathrm{py})_{3}\right)\right]\left(\mathrm{PF}_{6}\right)_{2}$ are collected following excitation with a $100 \mathrm{fs}$ optical pulse, and the results are compared with the steady-state X-ray absorption spectrum of its high-spin analogue, [Fe(tren(6-Mepy $\left.\left.)_{3}\right)\right]\left(\mathrm{PF}_{6}\right)_{2}$. The steady-state $\mathrm{X}$-ray absorption spectra show distinct XANES signatures for the different spin states and reveal an increase of $0.23 \AA$ in the $\mathrm{Fe}-\mathrm{N}$ bond length for the highspin analogue species. Transient pump-probe experiments observe that the structural and electronic changes following ${ }^{1} \mathrm{~A}_{1}$ $\rightarrow{ }^{1}$ MLCT excitation are complete within $70 \mathrm{ps}$ and the $\mathrm{Fe}-\mathrm{N}$ bond length is increased by $0.21 \AA$ in the photoexcited ${ }^{5} \mathrm{~T}_{2}$ highspin state. The dilation of the first coordination sphere explains all the observed transient spectral features, suggesting that the average $\mathrm{Fe}-\mathrm{N}$ bond length is a good reaction coordinate for following the $\mathrm{SCO}$ process of $\mathrm{Fe}^{\mathrm{II}}$ systems in solution using XAS.

\section{Methods}

2.1. Sample Preparation. $\left[\mathrm{Fe}\left(\operatorname{tren}(\mathrm{py})_{3}\right)\right]\left(\mathrm{PF}_{6}\right)_{2}$ and $[\mathrm{Fe}($ tren(6-Me-py $\left.\left.)_{3}\right)\right]\left(\mathrm{PF}_{6}\right)_{2}$ were prepared using previously published methods. ${ }^{33}$ HPLC grade $\mathrm{CH}_{3} \mathrm{CN}$ was purchased from Sigma Aldrich and used as received in the spectroscopic studies.

2.2. Experimental Techniques. Steady-state XAS on solutions of $\left[\mathrm{Fe}\left(\operatorname{tren}(\mathrm{py})_{3}\right)\right]\left(\mathrm{PF}_{6}\right)_{2}$ and $\left[\mathrm{Fe}\left(\operatorname{tren}(6-\mathrm{Me}-\mathrm{py})_{3}\right)\right]\left(\mathrm{PF}_{6}\right)_{2}$ was performed in fluorescence mode at the iron K-edge on beam line 10.3.2 at the ALS. A detailed description of the beam line has been reported previously. ${ }^{39}$ Briefly, the broadband X-ray source passes through a two-crystal $\mathrm{Si}$ (111) monochromator with a resolution of $1-2 \mathrm{eV}$, and the monochromatized light is focused onto the sample. Solutions of $\sim 0.02 \mathrm{M} \mathrm{Fe}^{\mathrm{II}}$ compounds dissolved in $\mathrm{CH}_{3} \mathrm{CN}$ were held in thin-walled quartz capillary tubes $(0.3 \mathrm{~mm}$ thick), which are mounted on a $x-y$ translation stage. The X-ray measurements are performed using a germanium solid-state detector. The fluorescence yield is normalized to the incident beam intensity and the dwell time of the detector. The spectral data are collected from 7017 to $7624 \mathrm{eV}$ in steps of $4 \mathrm{eV}$.

Transient XAS measurements are performed in transmission mode in a non-collinear pump-probe geometry on beam line 5.3.1 at the ALS, as illustrated in Figure 2. The experiment utilizes a special filling pattern of the ALS, which usually consists of 328 electron bunches each separated by $2 \mathrm{~ns}$. In this special mode, the ring is filled with 276 bunches separated by 


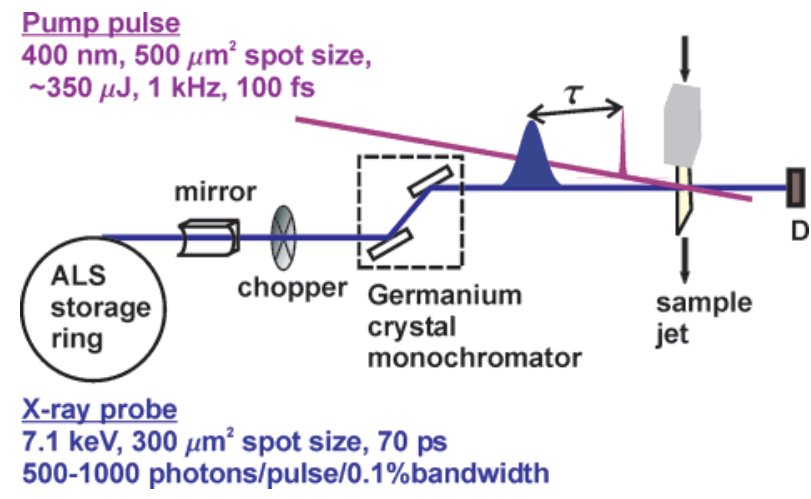

Figure 2. Layout of BL 5.3.1 at the ALS used for performing picosecond XAS experiments. The sample jet flows in a chamber purged with helium gas to minimize the absorption of the X-ray photons by air. Transmitted X-ray pulses are detected with a silicon avalanche photodiode (D).

$2 \mathrm{~ns}$ and contributing $1.4 \mathrm{~mA} /$ bunch to the total ring current. A single bunch contributing $10 \mathrm{~mA}$ is placed within the center of the 100 ns empty section and is known as the "camshaft pulse". The X-ray radiation from the camshaft pulse has a temporal width of $70 \mathrm{ps}$ and can be easily singled out using a fast photodiode making it suitable to use as a probe in time-resolved experiments. Monochromatic X-rays are selected by a twocrystal germanium (111) monochromator from 2 to $12 \mathrm{keV}$ with an energy resolution of $\sim 2.5 \mathrm{eV}$ at the Fe K-edge (7 keV). A mechanical chopper running at $2 \mathrm{kHz}$ is placed before the monochromator to reduce the $\mathrm{X}$-ray flux at the germanium crystals. To perform time-resolved experiments, the optical femtosecond pump pulse at $1 \mathrm{kHz}$ has to be synchronized with the X-ray probe pulse at $1.52 \mathrm{MHz}$. This is achieved by first synchronizing the femtosecond laser oscillator to the $500 \mathrm{MHz}$ radio frequency of the storage ring by adjusting the cavity length of the laser in a feedback loop. The laser amplifier selects a pulse from the oscillator every millisecond, and it is synchronized with the opening of the chopper window and to the 1.52 $\mathrm{MHz}$ revolution frequency of the ALS storage ring. This ensures that a femtosecond pump pulse is coincident on the sample with an X-ray probe pulse. The delay between the laser and X-ray pulses $(\tau)$ is set by a computer-controlled phase shifter, which adjusts the phase of the RF reference signal used to synchronize the laser oscillator. All subsequent triggers are changed accordingly.

A $100 \mathrm{fs}, 350 \mu \mathrm{J}, 400 \mathrm{~nm}$ pulse derived by frequency doubling the output of a $1 \mathrm{kHz}$ Ti:sapphire femtosecond laser system initiates the $\mathrm{Fe}^{\mathrm{II}}$ spin crossover transition in a sample consisting of a $0.5 \mathrm{~mm}$ thick free-flowing jet of $0.02 \mathrm{M}$ [Fe$\left.\left(\operatorname{tren}(\mathrm{py})_{3}\right)\right]\left(\mathrm{PF}_{6}\right)_{2}$ dissolved in acetonitrile at room temperature. The X-ray flux at the sample is between 500 and 1000 photons/ pulse $/ 0.1 \%$ bandwidth. The spot sizes of the laser and X-ray beams at the sample are $0.5 \times 0.5$ and $0.3 \times 0.1 \mathrm{~mm}^{2}$, respectively, and they cross at an angle of $30^{\circ}$. To ensure optimal overlap, the pulses are put through a $0.2 \mathrm{~mm}$ stainless steel pinhole placed at the focus of the beams. Temporal overlap is achieved by placing a fast silicon avalanche photodiode at the focal plane of the two beams and recording the traces on a 1 $\mathrm{GHz}$ oscilloscope. Time zero can be set to within $\pm 10 \mathrm{ps}$ in this manner with the aid of an electronic phase shifter. The X-ray photons transmitted through the sample are detected by a silicon avalanche photodiode.

Transient X-ray absorption spectra are collected at $2 \mathrm{kHz}$ to measure small difference signals relative to a reference spectrum. In this way we monitor the pairwise subtraction of two adjacent
X-ray pulses passing through the sample, $\Delta T=\left(I(\tau)-I_{\text {ref }}\right)$, where $I(\tau)$ and $I_{\text {ref }}$ refer to the XAS signals with and without the effect of the laser pulse, respectively. The difference signal $(\Delta T)$ is normalized with the $I_{\text {ref }}$ signal on a shot-to-shot basis to account for long-term drifts in the X-ray intensity. The collection scheme ensures that the experimental signal-to-noise ratio is dictated almost entirely by the shot noise limit of the $\mathrm{X}$-ray source. Energy-resolved measurements at a particular delay time are performed by tuning the monochromator crystals to select wavelengths from 7.1 to $7.3 \mathrm{keV}$ in $2 \mathrm{eV}$ steps. The data acquisition time for the energy resolved measurements is $\sim 20 \mathrm{~h}$. The sample is refreshed during the course of the experiment, and optical absorption measurements are performed regularly to check for sample integrity.

2.3. Data Analysis. Data reduction of the raw steady-state XAS signal shown in Figure 3 is done according to standard procedures. ${ }^{13,15}$ EXAFS structural parameters are determined using WinXas 3.0. ${ }^{40}$ For this purpose, $k^{3}$-weighted EXAFS spectra, where $k=\left(2 m\left(E-E_{0}\right) / \hbar^{2}\right)^{1 / 2}(m \equiv$ mass of an electron, $\left.E_{0}=7121 \mathrm{eV}\right)$, are Fourier transformed over the $2-11 \AA^{-1}$ range using a Bessel window. The spectra were fitted using the EXAFS formula:

$$
\chi(k)=\frac{N S_{0}^{2} F(k)}{k R^{2}} e^{\left(-2 k^{2} \sigma^{2}\right)} e^{(-2 R / \lambda)} \sin [2 k R+\delta(k)]
$$

where the backscattering amplitude, $F(k)$, phase, $\delta(k)$, and the photoelectron mean path, $\lambda$, are obtained from theoretical scattering functions calculated with FEFF 8.20 from the published crystal structures of $\left[\mathrm{Fe}\left(\operatorname{tren}(\mathrm{py})_{3}\right)\right]\left(\mathrm{PF}_{6}\right)_{2}$ and $[\mathrm{Fe}-$ $\left.\left(\operatorname{tren}(6-\mathrm{Me}-\mathrm{py})_{3}\right)\right]\left(\mathrm{PF}_{6}\right)_{2} \cdot{ }^{34,35}$ The following parameters were allowed to vary in the fitting routine: the $\mathrm{Fe}-\mathrm{N}$ bond length, $R$, the coordination number, $N$, and the Debye - Waller factor accounting for thermal and static disorder, $\sigma^{2}$. The value of the amplitude reduction factor, $S_{0}^{2}$, is held constant at 0.72 in all the fits. The fits are performed both in $k\left(\AA^{-1}\right)$ and its Fourier conjugate, $R(\AA)$ space, to check for consistency.

The calculation of the XANES spectra for the reactant and transient photoproduct species, shown in Figure 5b, were performed using FEFF 8.20. ${ }^{14,41}$ The code carried out a full multiple scattering XANES calculation for an atomic cluster of radius $6.0 \AA$ centered on the Fe atom. The angular momentum projected density of states was calculated using the LDOS routine in the FEFF 8.20 code from -20 to $40 \mathrm{eV}$ with a Lorentzian broadening of $0.02 \mathrm{eV}$. The atomic coordinates from the published crystal structure of the low-spin reactant species were used for calculating the reactant spectrum. The structure was modified by lengthening the $\mathrm{Fe}-\mathrm{N}$ bonds by $0.2 \AA$ and then used to simulate the XANES spectrum of the transient species.

\section{Results and Discussion}

3.1. X-ray Absorption Spectroscopy of the Ground-State Low- and High-Spin Fe ${ }^{\text {II }}$ Compounds. Figure 3 a displays the significantly different XANES spectra of $\left[\mathrm{Fe}\left(\operatorname{tren}\left(\mathrm{py}_{3}\right)_{3}\right)\right]\left(\mathrm{PF}_{6}\right)_{2}$ (solid line) and $\left[\mathrm{Fe}\left(\operatorname{tren}(6-\mathrm{Me}-\mathrm{py})_{3}\right)\right]\left(\mathrm{PF}_{6}\right)_{2}$ (dashed line) complexes dissolved in $\mathrm{CH}_{3} \mathrm{CN}$. To aid the discussion, various spectral features for the low-spin and the high-spin analogue compounds have been labeled. A comparison of the two spectra reveals that (i) the intensity of the shoulder labeled A at 7124 $\mathrm{eV}$ in the spectrum of the low-spin compound increases to $\mathrm{A}^{\prime}$ for the high-spin complex, (ii) the main resonance shifts to lower energies from B $(7131 \mathrm{eV})$ to $\mathrm{B}^{\prime}(7128 \mathrm{eV})$, (iii) the shoulder at $\mathrm{C}(7142 \mathrm{eV})$ loses intensity, and (iv) the broad peak at D 

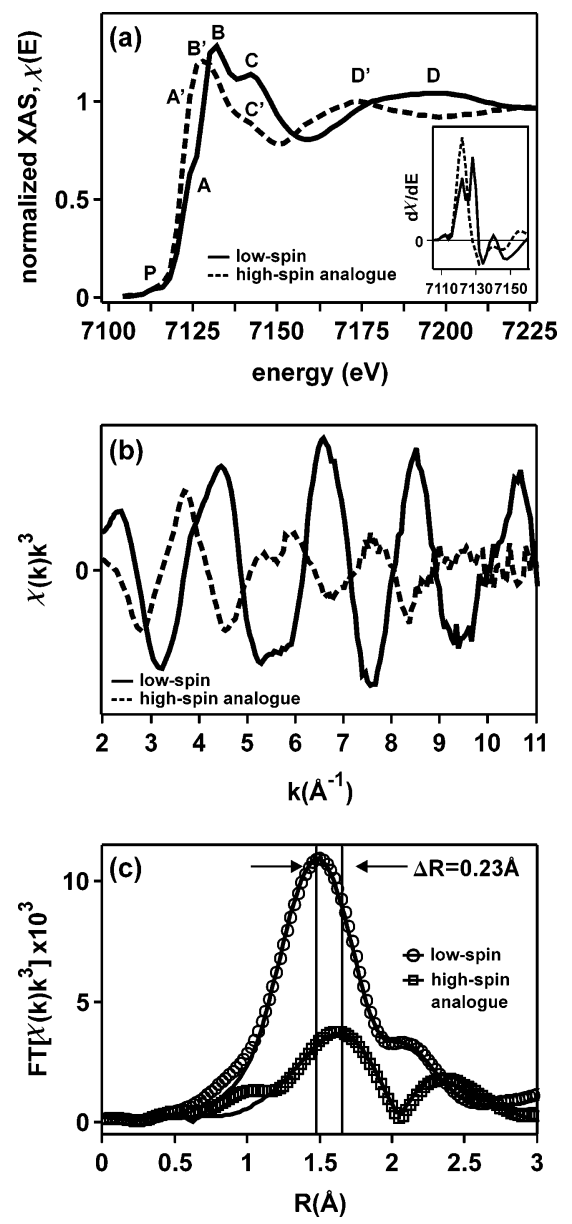

Figure 3. Room-temperature steady-state XAS spectra of [Fe(tren$\left.\left.(\text { py })_{3}\right)\right]\left(\mathrm{PF}_{6}\right)_{2}$ (low-spin) and $\left[\mathrm{Fe}\left(\operatorname{tren}(6-\mathrm{Me}-\mathrm{py})_{3}\right)\right]\left(\mathrm{PF}_{6}\right)_{2}$ (high-spin) compounds in $\mathrm{CH}_{3} \mathrm{CN}$ solution at the $\mathrm{Fe} \mathrm{K}$-edge. The spectra were acquired in the fluorescence mode at beam line 10.3.1 at the ALS. (a) XANES spectra of the low-spin (solid line) and the high-spin analogue (dashed line) plotted as normalized X-ray absorption, where $\chi(E)=$ $\left[\mu(E)-\mu\left(E_{0}\right)\right] / \mu\left(E_{0}\right)$ and $\mu=I_{\mathrm{f}} / I_{0}$. The parameters $I_{\mathrm{f}}$ and $I_{0}$ refer to the X-ray fluorescence from the sample and the background signals, respectively. The value of $E_{0}=7121 \mathrm{eV}$ used to normalize the spectra is obtained by taking the root of the first derivative of the $1 \mathrm{~s} \rightarrow 4 \mathrm{p}$ transition in the low-spin XANES spectrum. The derivatives of the XANES spectra are plotted in the inset to highlight the differences in spectral positions and amplitudes for the two distinct $\mathrm{Fe}^{\mathrm{II}}$ compounds. (b) EXAFS spectra of $\left[\mathrm{Fe}\left(\operatorname{tren}(\mathrm{py})_{3}\right)\right]\left(\mathrm{PF}_{6}\right)_{2}$ and $\left[\mathrm{Fe}\left(\operatorname{tren}(6-\mathrm{Me}-\mathrm{py})_{3}\right)\right]-$ $\left(\mathrm{PF}_{6}\right)_{2}$ weighted by $k^{3}$. (c) Fourier transformed EXAFS spectra of the above species weighted by $k^{3}$. The solid lines correspond to the fits of the data in $R$ space, yielding the parameters listed in Table 1 . The peaks represent the nearest-neighbor $\mathrm{Fe}-\mathrm{N}$ bond distances $(R)$. Note that the spectra are not corrected for the phases, so the displayed distances are shorter that the actual distances listed in Table 1.

( $\sim 198 \mathrm{eV})$ shifts to lower energy D' (7174 eV). In addition, there is a weak preedge feature $\mathrm{P}$, present in both spectra at $7114 \mathrm{eV}$. The XANES derivative spectra plotted in the inset of Figure $3 \mathrm{a}$ also highlight the differences in the positions and amplitudes of the spectral features discussed above. Figure $3 b$ shows the $k^{3}$-weighted EXAFS spectra of the low-spin and highspin analogue complexes. We see that the frequency, amplitude, and phase of the detected wave vector is different for the two spin states, indicating their distinct molecular geometries. The Fourier transform of the EXAFS spectra are plotted below in Figure 3c. The position of the first major peak in each spectrum corresponds to the radius of the first coordination shell around the $\mathrm{Fe}$ atom. We can see that the average $\mathrm{Fe}-\mathrm{N}$ bond length is $\sim 0.23 \AA$ longer in the high-spin analogue complex with respect to the low-spin complex.
TABLE 1: Best-fit Values for the Structures of the Equilibrium and Transient $\mathrm{Fe}^{\mathrm{II}}$ Complexes Dissolved in $\mathrm{CH}_{3} \mathrm{CN}^{a}$

\begin{tabular}{lccc}
\hline compound & $\mathrm{N}^{\mathrm{b}}$ & $R,{ }^{c} \AA$ & $\sigma^{2},{ }^{d} \AA^{2}$ \\
\hline$\left[\mathrm{Fe}\left(\operatorname{tren}(\mathrm{py})_{3}\right)\right]\left(\mathrm{PF}_{6}\right)_{2}$ & $6.0 \pm 0.5$ & $1.96 \pm 0.01$ & $0.0020 \pm 0.0001$ \\
{$\left[\mathrm{Fe}\left(\operatorname{tren}\left(6-\mathrm{Me}-\mathrm{py}_{3}\right)\right]\right.$} & $6.0 \pm 0.5$ & $2.19 \pm 0.01$ & $0.0130 \pm 0.0001$ \\
{$\left[\mathrm{Fe}\left(\operatorname{tren}(\mathrm{py})_{3}\right)\right]\left(\mathrm{PF}_{6}\right)_{2}$} & $6.0 \pm 1.0$ & $2.17 \pm 0.03$ & $0.011 \pm 0.001$ \\
at $\Delta \tau=330 \mathrm{ps}$ following & & & \\
excitation at $400 \mathrm{~nm}$ & & & \\
${ }^{a}$ The value of $S_{0}{ }^{2}$ is held constant at 0.72 in all these fits. \\
${ }^{b}$ Coordination number. ${ }^{c} \mathrm{Fe}-\mathrm{N}$ bond length. ${ }^{d}$ Disorder parameter.
\end{tabular}

The first two rows of Table 1 list EXAFS fitting results displaying the coordination number, the $\mathrm{Fe}-\mathrm{N}$ bond lengths, and the disorder factors of the $\mathrm{Fe}^{\mathrm{II}}$ complexes. The fits are displayed as solid lines in Figure 3c. The increase in the DebyeWaller disorder factor from $0.002 \AA^{2}$ for the low-spin complex to $0.013 \AA^{2}$ for the high-spin species accounts for the decrease in intensity of the peaks and the oscillations in the Fourier transform spectra of Figure $3 \mathrm{c}$ and the EXAFS spectra of Figure 3b. The average $\mathrm{Fe}-\mathrm{N}$ distance for $\left[\mathrm{Fe}\left(\operatorname{tren}(\mathrm{py})_{3}\right)\right]^{2+}$ of $1.96 \AA$ agrees well with the published average distance of $1.95 \AA .{ }^{35}$ Single-crystal studies of the high-spin analogue report two distinct $\mathrm{Fe}-\mathrm{N}$ bond lengths of 2.14 and $2.28 \AA$ corresponding to the bonding of the $\mathrm{Fe}-\mathrm{N}$ (imine) and $\mathrm{Fe}-\mathrm{N}$ (pyridine) ligands, respectively. ${ }^{34}$ However, the solution EXAFS data of the highspin analogue is best fit by a single $\mathrm{Fe}-\mathrm{N}$ distance of $2.19 \AA$. The slight discrepancy, which corresponds roughly to a weighted average of the two crystallographically determined values, is likely due to the dynamic nature of molecular structures in solution. A comparison of the fits in the $k$ and $R$ space and the fitting of the high-spin data with one and two $\mathrm{Fe}-\mathrm{N}$ bond distances can be found in the Supporting Information.

The significant elongation of the $\mathrm{Fe}-\mathrm{N}$ bond, reflecting the difference in electronic configuration between the low-spin and high-spin compounds, accounts for all the features observed in the XANES spectra. The origin of the spectral features in the XANES region of similar low-spin and high-spin $\mathrm{Fe}^{\mathrm{II}}$ complexes has been discussed in detail elsewhere. ${ }^{42-44}$ The preedge peak, $\mathrm{P}$, is due to the forbidden $1 \mathrm{~s} \rightarrow 3 \mathrm{~d}$ transition. Its presence in the XANES spectra indicates a slight distortion from perfect octahedral symmetry, leading to increased mixing between the metal ( $3 d$ and $4 p)$ and ligand orbitals in lower symmetry. The fact that the amplitude of peak $P$ remains the same for both complexes suggests that the degree of distortion from a perfect octahedral symmetry around the iron atom is similar in both spin states.

In the XANES region, $\mathrm{A}\left(\mathrm{A}^{\prime}\right)$ and $\mathrm{B}\left(\mathrm{B}^{\prime}\right)$ arise from transitions to the lowest unoccupied metal states. These unoccupied orbitals result from mixing between the $\mathrm{Fe}(4 \mathrm{~s}, 4 \mathrm{p})$ and the $\mathrm{N}(2 \mathrm{p})$ states. As the $\mathrm{Fe}-\mathrm{N}$ bond length increases (i.e. upon going from the low-spin to the high-spin state), the overlap between the metal atom and ligand orbitals diminishes. This effect has two consequences: (i) the metal orbitals have less ligand character, resulting in an increase in the intensity of the $1 \mathrm{~s} \rightarrow 4 \mathrm{p}$ transition (A') and (ii) since the transition involves an orbital that is formally antibonding in nature, the increase in bond length lowers the energy of the unoccupied $\mathrm{Fe}(4 \mathrm{~s}, 4 \mathrm{p})-\mathrm{N}(2 \mathrm{p})$ state $(\mathrm{s})$, accounting for the $\sim 3 \mathrm{eV}$ red shift of feature $\mathrm{B}^{\prime}$. The shoulder labeled $\mathrm{C}\left(\mathrm{C}^{\prime}\right)$ has been attributed to multiple scattering processes in similar $\mathrm{Fe}^{\mathrm{II}}$ complexes. ${ }^{42}$ While a specific assignment is difficult, its change in intensity in Figure $3 \mathrm{a}$ is diagnostic of the geometrical difference between the low-spin and high-spin complexes. Finally, the broad features $\mathrm{D}\left(\mathrm{D}^{\prime}\right)$ arise from scattering of the photoelectron by the nearest-neighbor nitrogen shell. ${ }^{43}$ Their spectral positions can be related by Natoli's rule, 

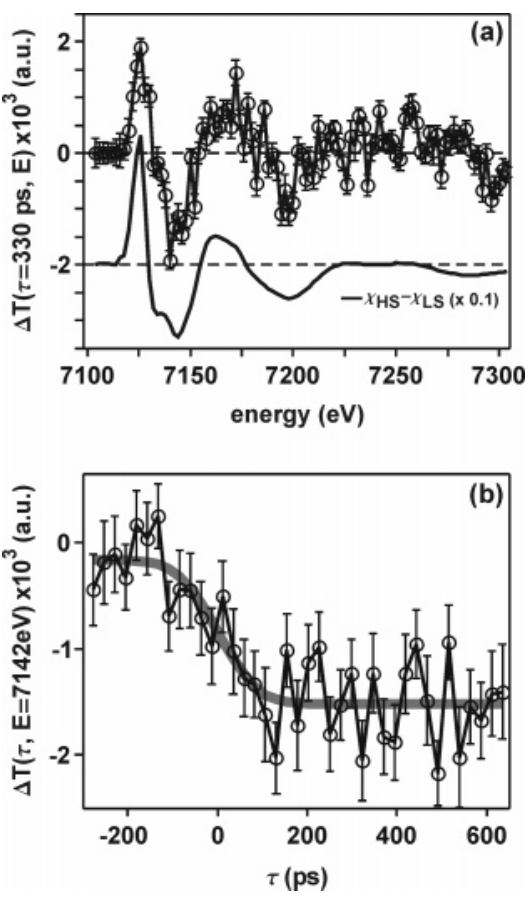

Figure 4. Time-resolved X-ray absorption difference spectroscopy of the ultrafast $\mathrm{SCO}$ process in $\left[\mathrm{Fe}\left(\operatorname{tren}(\mathrm{py})_{3}\right)\right]\left(\mathrm{PF}_{6}\right)_{2}$ in $\mathrm{CH}_{3} \mathrm{CN}$ solution. (a) Transient difference X-ray absorption spectrum recorded $330 \mathrm{ps}$ after ${ }^{1} \mathrm{~A}_{1} \rightarrow{ }^{1} \mathrm{MLCT}$ excitation at $400 \mathrm{~nm}$ (open circles). The difference between the steady-state XAS spectra of the high-spin and low-spin compounds from Figure $3 \mathrm{a}$ is plotted below. (b) Pump-probe X-ray absorption signal (open circles) at $7142 \mathrm{eV}$ as a function of the delay time between the laser and X-ray pulses $(\tau)$. The thick gray solid line is a fit of the data using a cross-correlation width of $70 \mathrm{ps}$. This value is dictated by the X-ray pulse width and corresponds to the temporal resolution of the experiment.

$\Delta E \times R^{2}=$ constant, where $\Delta E$ is the energy of feature $\mathrm{D}\left(\mathrm{D}^{\prime}\right)$ relative to a given reference energy and $R$ is the mean $\mathrm{Fe}-\mathrm{N}$ bond length in the $\mathrm{Fe}^{\mathrm{II}}$ compounds. ${ }^{45-47}$ Taking the K-edge energy of an Fe foil as our reference $(7112 \mathrm{eV})$, the experimentally obtained ratio of $\sqrt{\Delta E}$ for the low-spin and high-spin forms is $\sim 0.9$, which is consistent with the observed change in the $\mathrm{Fe}-\mathrm{N}$ bond lengths of the two spin complexes shown in Figure $3 \mathrm{c}$. Our observations agree with steady-state measurements made on other $\mathrm{Fe}^{\mathrm{II}}$ spin-crossover complexes in the solid state and in solution. ${ }^{42,44,47-51}$

The steady-state XAS spectra of the $\mathrm{Fe}^{\mathrm{II}}$ complexes with different substitutions on the hexadentate ligand allow us to map out the distinguishing spectroscopic features for the low-spin and high-spin electronic configurations. However, they do not provide any information about the dynamic relationship between molecular structure and the ultrafast SCO transition. To shed light on this complex problem, we use time-resolved picosecond XAS to probe the transient structural changes in the excitedstate evolution of $\left[\mathrm{Fe}\left(\operatorname{tren}(\mathrm{py})_{3}\right)\right]^{2+}$ following ${ }^{1} \mathrm{~A}_{1} \rightarrow{ }^{1} \mathrm{MLCT}$ excitation in solution.

3.2. Transient Structural Changes during the Photoinduced SCO Process. Figure 4a shows the transient difference absorption spectrum of $\left[\mathrm{Fe}\left(\operatorname{tren}(\mathrm{py})_{3}\right)\right]\left(\mathrm{PF}_{6}\right)_{2}$ as a function of the X-ray energy at the Fe K-edge, $330 \mathrm{ps}$ after laser excitation (open circles). This difference spectrum probes the changes in the electron density around the Fe atom after the ${ }^{1} \mathrm{~A}_{1} \rightarrow{ }^{1}$ MLCT excitation, but prior to the ground-state recovery. ${ }^{37}$ For comparison, the difference absorption spectrum of the ground-state high-spin complex $\left(\left[\mathrm{Fe}\left(\operatorname{tren}(6-\mathrm{Me}-\mathrm{py})_{3}\right)\right]\left(\mathrm{PF}_{6}\right)_{2}\right)$ and $[\mathrm{Fe}($ tren$\left.\left.(\mathrm{py})_{3}\right)\right]\left(\mathrm{PF}_{6}\right)_{2}$, obtained from the steady-state measurements, is plotted below the transient data in Figure 4a. The steady-state difference spectrum is scaled by a factor of 0.1 to account for the $10 \%$ photoexcitation of the ground-state species in solution by the laser pump pulse. It can be seen that the two data sets are strikingly similar in virtually all respects. In particular, the following distinguishing spectral characteristics of the transient ${ }^{5} \mathrm{~T}_{2}$ state with respect to the ground state ${ }^{1} \mathrm{~A}_{1}$, are observed (see Figure $3 \mathrm{a}$ for the labeled spectral features): (i) there is no change in the amplitude of the preedge feature P, (ii) the intensity of spectral feature A increases, (iii) there is a change in the position of the feature B, and (iv) the amplitude of feature $\mathrm{C}$ decreases. Additionally, changes in the bond lengths are indicated by the oscillations at higher energies.

To study the time evolution of the spectral features as a function of the delay between the visible pump and X-ray probe pulses $(\tau$ ), we performed a time-resolved scan at $7142 \mathrm{eV}$ (peak $\mathrm{C}$ in Figure 3a), and these results are plotted in Figure 4b. The results show a decrease in the amplitude of the spectral feature at $7142 \mathrm{eV}$ following photoexcitation of the low-spin compound. This observation is consistent with the steady-state spectra plotted in Figure 3a and discussed in the previous section. The time-resolved measurements reveal that the spectral change at $7142 \mathrm{eV}\left(k=2.1 \AA^{-1}\right)$ is fully complete within the first $100 \mathrm{ps}$ after the charge-transfer excitation of the low-spin compound. The temporal evolution of the difference X-ray signal is modeled as a step function convoluted with the instrument response time. It is fitted by a Gaussian error function (thick solid curve) with a width of $70 \pm 10 \mathrm{ps}$. This width corresponds to the X-ray pulse duration and indicates that the structural evolution following ${ }^{1} \mathrm{~A}_{1} \rightarrow{ }^{1} \mathrm{MLCT}$ excitation of the low-spin compound, $\left[\mathrm{Fe}\left(\operatorname{tren}(\mathrm{py})_{3}\right)\right]\left(\mathrm{PF}_{6}\right)_{2}$, dissolved in $\mathrm{CH}_{3} \mathrm{CN}$ is complete within the time resolution of our experiment.

We fit the difference XAS spectrum obtained at $\tau=330 \mathrm{ps}$ (Figure 4a) to determine the structure of the transient ${ }^{5} \mathrm{~T}_{2}$ highspin state. The fitting is performed in $k$ space (data are shown as open circles in Figure 5a) from 1 to $7 \AA^{-1}$ using the expression, $\Delta T(k, \tau)=f(\tau)\left[I(k, \tau)-I_{\mathrm{ref}}(k)\right]$, where $I(k, \tau)$ and $I_{\text {ref }}(k)$ are the transmitted signals for the excited- and groundstate species, respectively, and $f(\tau)$ is the fraction of photoexcited species present at delay time $\tau$ in the solution. The structural parameters used for the EXAFS fit to the ground state $\left(I_{\text {ref }}(k)\right)$ are listed in the first row of Table 1 and are held constant during the fitting procedure. For the transient excited-state species (i.e. the high-spin ${ }^{5} \mathrm{~T}_{2}$ state), the $\mathrm{Fe}-\mathrm{N}$ bond length, the coordination number, and the disorder parameter are free parameters in the fitting procedure. The value of $f(\tau)$ is estimated to be $10 \%$ from optical absorption data and is held constant in the fit. The $k$ space fit (solid gray line) is shown in Figure 5a and is in good agreement with the data from the differential XAS (open circles). The results from the fitting procedure are listed in the last row of Table 1, revealing that the $\mathrm{Fe}-\mathrm{N}$ bond length has lengthened to $2.17 \pm 0.03 \AA$ at $\tau=330 \mathrm{ps}$ from an initial value of $1.96 \pm$ $0.01 \AA$ A.

Using the structural parameters obtained from the timeresolved EXAFS data, we simulated the XANES spectra of the ground state and the transient excited state. The results are plotted in Figure 5b. The spectra were simulated with FEFF 8.20 , which uses an ab initio based self-consistent real space multiple scattering algorithm. ${ }^{41}$ The calculated low-spin groundstate spectrum (solid line in Figure 5b) reproduces all the relative amplitudes and positions of the major spectroscopic signatures present in the experimental data of Figure 3a. To understand the effect of the elongation of the $\mathrm{Fe}-\mathrm{N}$ bond length in the XANES region, we modified the crystal structure of the lowspin complex by lengthening the $\mathrm{Fe}-\mathrm{N}$ bonds by $0.2 \AA$, and 
(a)

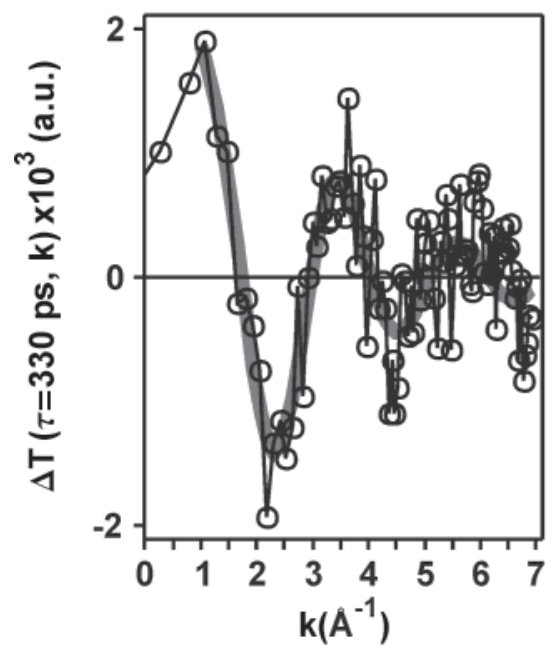

(b)

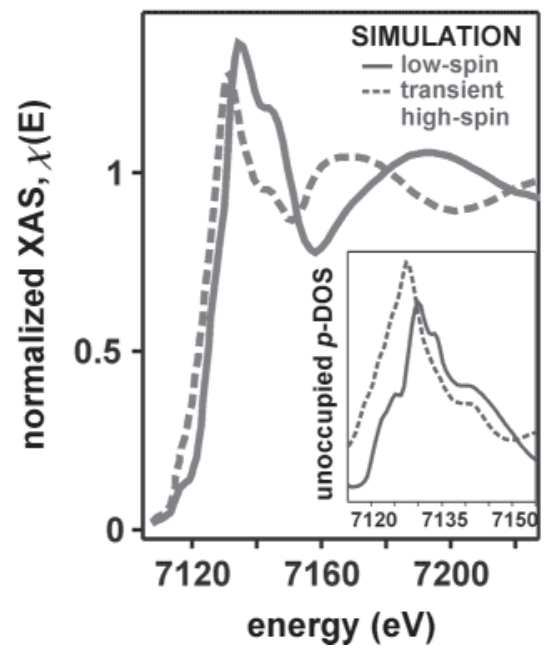

(c)

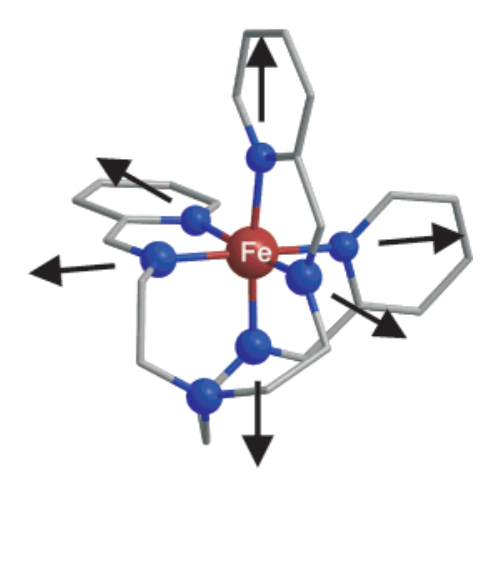

Figure 5. Modeling the transient structural and electronic changes following the ${ }^{1} \mathrm{~A}_{1} \rightarrow{ }^{1} \mathrm{MLCT}$ excitation of $\left[\mathrm{Fe}\left(\operatorname{tren}(\mathrm{py})_{3}\right)\right]\left(\mathrm{PF}_{6}\right)_{2}$ in $\mathrm{CH}_{3} \mathrm{CN}$ solution. (a) Transient EXAFS signal (open circles) and the best-fit to the data (gray solid line), revealing an increase in the Fe-N bond length of $0.21 \AA$ in the ${ }^{5} \mathrm{~T}_{2}$ excited state. Given the signal-to-noise constraints of the data, only changes to the first coordination shell are accounted for in the fitting process. (b) Simulated XANES spectra of the ground state (gray solid line) and transient (gray dashed line) species at $\tau=330$ ps. The projected unoccupied density of states (DOS) of the metal $\mathrm{p}$ states is plotted in the inset. The simulation of the ground-state compound was performed using the real space multiple scattering code FEFF 8.20 using the published crystal structure of $\left[\mathrm{Fe}\left(\operatorname{tren}(\mathrm{py})_{3}\right)\right]^{2+}$. The transient XANES spectrum was calculated by lengthening the $\mathrm{Fe}-\mathrm{N}$ bonds of the first coordination shell. All the experimental trends are qualitatively reproduced by the calculation. (c) Structure of the $\mathrm{Fe}^{\mathrm{II}}$ compound used in this study (the nitrogen atoms are colored blue), demonstrating the structural changes that take place during the course of the photoinduced SCO process.

simulated the spectrum using FEFF 8.20. As expected, the simulated transient XANES spectrum shown as the dashed line in Figure $5 b$ is reminiscent of the steady-state spectrum of [Fe(tren(6-Me-py) $\left.\left.)_{3}\right)\right]\left(\mathrm{PF}_{6}\right)_{2}$ shown in Figure 3a. Comparing the two simulated spectra in Figure 5b, we see that the intensity of peak A increases, the position of feature B shifts by $3 \mathrm{eV}$, and the frequency and phase of the EXAFS oscillations change as a result of the ${ }^{1} \mathrm{~A}_{1} \rightarrow{ }^{1}$ MLCT excitation.

The projected unoccupied density of p-states (p-DOS) of the Fe atom is plotted in the inset of Figure $5 \mathrm{~b}$. We note that as the $\mathrm{Fe}-\mathrm{N}$ bond is lengthened during the reaction, the unoccupied p-DOS increases in amplitude and shifts to the red by $3 \mathrm{eV}$. These results are consistent with the features observed in the XANES spectra, since the spectral features A and B involve transitions from the core metal 1s level to unoccupied $4 p$ states that mix with the ligand $2 p$ orbitals. From the fits of the timeand energy-resolved transient data and the modeling, we can summarize that the ${ }^{5} \mathrm{~T}_{2}$ excited high-spin state of $\left[\mathrm{Fe}\left(\operatorname{tren}(\mathrm{py})_{3}\right)\right]$ $\left(\mathrm{PF}_{6}\right)_{2}$ is characterized by a lengthening of the first coordination sphere by $\sim 0.2 \AA$ and that this transformation occurs within 70 ps. This is illustrated in the last panel of Figure 5, which shows the crystal structure of the ground state with arrows indicating the subsequent changes in the structure upon the photoinduced ${ }^{1} \mathrm{~A}_{1} \rightarrow{ }^{5} \mathrm{~T}_{2}$ conversion of the molecule in solution.

The work presented in this paper stands in contrast to previous XAS studies of SCO systems, which exploited the LIESST (light-induced excited-state trapping) effect to gain information about the structural characteristics of the high-spin state. ${ }^{52,53}$ The LIESST effect involves "trapping" the high-spin state of a solid SCO compound by lowering its temperature and irradiating it with an incoherent light source to yield an almost complete conversion of the solid sample to its high-spin form. In this study, we impulsively photoinduce a spin crossover transition in an $\mathrm{Fe}^{\mathrm{II}}$ compound in solution and then directly probe the electronic and structural properties of the transient population of the high-spin ${ }^{5} \mathrm{~T}_{2}$ state at ambient temperature. Our results reveal that, within the experimental signal-to-noise ratio, the structure of the transient high-spin state of our $\mathrm{Fe}^{\mathrm{II}}$ system fully develops within $70 \mathrm{ps}$ and is similar to the previously measured structures of other Fe ${ }^{\mathrm{II}}$ compounds in their "trapped" high-spin states. ${ }^{4-51}$ Additionally, the lack of change in the preedge feature $\mathrm{P}$, at $7114 \mathrm{eV}$ in the transient XANES signal, suggests that there is little change in the pseudooctahedral symmetry of the iron atom $70 \mathrm{ps}$ after the SCO process has been initiated. The measured structural changes along the $\mathrm{Fe}-\mathrm{N}$ bond coordinate also account for the local electronic changes around the iron atom as observed by the altered unoccupied p-DOS of the transient species.

Given that the ${ }^{1} \mathrm{MLCT} \rightarrow{ }^{5} \mathrm{~T}_{2}$ relaxation rate of these $\mathrm{Fe}^{\mathrm{II}}$ compounds in a room-temperature solution is $>10^{12} \mathrm{~s}^{-1}, 11,37$ our present time resolution of 70 ps prevents us from directly tracking the structural changes along the reaction coordinate(s) during these early events. However, future experiments at the Fe K-edge using femtosecond X-ray pulses at the ALS will enable us to discern these structural dynamics. Femtosecond XAS experiments at the Fe L-edge, which is sensitive to the population of the $3 \mathrm{~d}$ electrons, will also be crucial for understanding the electronic reorganization pathways responsible for the highly efficient intersystem crossing in the $\mathrm{Fe}^{\mathrm{II}} \mathrm{SCO}$ complexes.

\section{Conclusion}

In summary, synchrotron-based picosecond XAS has provided the first direct insight into the atomic structural changes associated with the spin crossover transition of an iron(II) complex in solution with $0.03 \AA$ spatial and 70 ps temporal resolution. Our results show that within our time resolution and the signal-to-noise of the data, the average $\mathrm{Fe}-\mathrm{N}$ bond length is a good reaction coordinate for describing this prototypical intramolecular electron-transfer reaction in solution. This experiment along with other recent efforts paves the way for future femtosecond X-ray absorption studies of solution phase chemistry at synchrotron sources and at the Advanced Light Source in particular. We anticipate a bright future for the technique of 
time-resolved XAS with the availability of femtosecond, tunable (150 eV to $10 \mathrm{keV}$ ), high flux ( $>10^{8}$ photons/pulse/0.1\% bandwidth at the sample) X-ray sources. The ability of ultrafast XAS to measure structural changes with high spatial and temporal resolution around specific elements in solution will impact a wide range of scientific disciplines. Particularly exciting is the potential ability to directly follow specific local structural changes occurring on the ground and excited electronic states in important chemical and biological systems.

Acknowledgment. This research was supported by the Director, Office of Science, Office of Basic Energy Sciences, and Materials Sciences Division, of the U.S. Department of Energy under Contract No. DE-AC02-05CH11231 at the Lawrence Berkeley National Laboratory and the Chemical Sciences Division under Grant No. DE-FG02-01ER15282 (J.K.M.) at Michigan State University. M.K. acknowledges the fellowship support of the Miller Institute for Basic Research in Science and thanks Professor Stephen R. Leone for stimulating discussions and a critical reading of the manuscript.

Supporting Information Available: A comparison of the fits to the EXAFS spectra using one and two $\mathrm{Fe}-\mathrm{N}$ bond lengths (Figures S1 and S2). This material is available free of charge via the Internet at http://pubs.acs.org.

\section{References and Notes}

(1) Fleming, G. R. Chemical applications of ultrafast spectroscopy; Oxford University Press: Oxford [Oxfordshire], New York, 1986.

(2) Sundström, V. Femtochemistry and femtobiology: Ultrafast reaction dynamics at atomic-scale resolution; Nobel Symposium 101; London: Imperial College Press: River Edge, NJ, 1997.

(3) Gütlich, P.; Goodwin, H. A. Spin crossover in transition metal compounds I-III; Springer: London, Berlin, 2004.

(4) Beattie, J. K. Adv. Inorg. Chem. 1988, 32, 1.

(5) Franzen, S. P. Natl. Acad. Sci. U.S.A. 2002, 99, 16754

(6) Letard, J. F.; Guionneau, P.; Goux-Capes, L. Top. Curr. Chem. 2004, 235, 221

(7) Cambi, L.; Szego, L. Ber. Dtsch. Chem. Ges. B 1933, 66, 656.

(8) Cambi, L.; Szego, L. Ber. Dtsch. Chem. Ges. B 1931, 64, 2591.

(9) Gutlich, P.; Hauser, A.; Spiering, H. Angew. Chem., Int. Ed. Engl. 1994, 33, 2024

(10) Gutlich, P.; Garcia, Y.; Goodwin, H. A. Chem. Soc. Rev. 2000 29,419 .

(11) Brady, C.; McGarvey, J. J.; McCusker, J. K.; Toftlund, H.; Hendrickson, D. N. Top. Curr. Chem. 2004, 235, 1.

(12) Solomon, E. I. Coord. Chem. Rev. 2005, 249, 1.

(13) Koningsberger, D. C.; Prins, R. X-ray absorption: Principles, applications, techniques of EXAFS, SEXAFS and XANES; John Wiley \& Sons: New York, 1988; Vol. 92.

(14) Rehr, J. J.; Ankudinov, A. L. Coord. Chem. Rev. 2005, 249, 131.

(15) Teo, B. K. EXAFS: Basic principles and data analysis; SpringerVerlag: New York, Berlin, 1986

(16) Eisenberger, P.; Kincaid, B. M. Science 1978, 200, 1441.

(17) Bressler, C.; Saes, M.; Chergui, M.; Grolimund, D.; Abela, R.; Pattison, P. J. Chem. Phys. 2002, 116, 2955.

(18) Saes, M.; Bressler, C.; Abela, R.; Grolimund, D.; Johnson, S. L.; Heimann, P. A.; Chergui, M. Phys. Rev. Lett. 2003, 90.
(19) Saes, M.; Bressler, C.; van Mourik, F.; Gawelda, W.; Kaiser, M. Chergui, M.; Bressler, C.; Grolimund, D.; Abela, R.; Glover, T. E.; Heimann, P. A.; Schoenlein, R. W.; Johnson, S. L.; Lindenberg, A. M.; Falcone, R. W. Rev. Sci. Instrum. 2004, 75, 24.

(20) Chen, L. X.; Jager, W. J. H.; Jennings, G.; Gosztola, D. J Munkholm, A.; Hessler, J. P. Science 2001, 292, 262.

(21) Lee, T.; Jiang, Y.; Rose-Petruck, C. G.; Benesch, F. J. Chem. Phys 2005, 122

(22) Chen, L. X.; Shaw, G. B.; Novozhilova, I.; Liu, T.; Jennings, G.; Attenkofer, K.; Meyer, G. J.; Coppens, P. J. Am. Chem. Soc. 2003, 125, 7022.

(23) Tomov, I. V.; Oulianov, D. A.; Chen, P. L.; Rentzepis, P. M. J. Phys. Chem. B 1999, 103, 7081 .

(24) Schoenlein, R. W.; Chattopadhyay, S.; Chong, H. H. W.; Glover, T. E.; Heimann, P. A.; Leemans, W. P.; Shank, C. V.; Zholents, A.; Zolotorev, M. Appl. Phys. B: Lasers Opt. 2000, 71, 1.

(25) Schoenlein, R. W.; Chattopadhyay, S.; Chong, H. H. W.; Glover, T. E.; Heimann, P. A.; Shank, C. V.; Zholents, A. A.; Zolotorev, M. S. Science 2000, 287, 2237.

(26) Chen, L. X. Angew. Chem., Int. Ed. 2004, 43, 2886.

(27) Chen, L. X. Аппи. Rev. Phys. Chem. 2005, 56, 221.

(28) Bressler, C.; Chergui, M. Chem. Rev. 2004, 104, 1781.

(29) Plech, A.; Wulff, M.; Bratos, S.; Mirloup, F.; Vuilleumier, R.; Schotte, F.; Anfinrud, P. A. Phys. Rev. Lett. 2004, 92.

(30) Schotte, F.; Lim, M. H.; Jackson, T. A.; Smirnov, A. V.; Soman, J.; Olson, J. S.; Phillips, G. N.; Wulff, M.; Anfinrud, P. A. Science 2003 300,1944

(31) DeCamp, M. F.; Reis, D. A.; Fritz, D. M.; Bucksbaum, P. H.; Dufresne, E. M.; Clarke, R. J. Synchrotron Radiat. 2005, 12, 177.

(32) Lindenberg, A. M.; Kang, I.; Johnson, S. L.; Missalla, T.; Heimann, P. A.; Chang, Z.; Larsson, J.; Bucksbaum, P. H.; Kapteyn, H. C.; Padmore, H. A.; Lee, R. W.; Wark, J. S.; Falcone, R. W. Phys. Rev. Lett. 2000, 84, 111.

(33) Hoselton, M. A.; Wilson, L. J.; Drago, R. S. J. Am. Chem. Soc 1975, 97, 1722

(34) Delker, G. L. Temperature-dependent studies on structural and electronic effects in single crystals. Ph.D. Thesis, University of Illinois, Urbana-Champaign, IL, 1976.

(35) Boubekeur, K.; Deroche, A.; Lambert, F.; Morgensternbadarau, I. Acta Crystallogr., Sect. C: Cryst. Struct. Commun. 1995, 51, 2244.

(36) Wilson, L. J.; Georges, D.; Hoselton, M. A. Inorg. Chem. 1975, 14, 2968

(37) Monat, J. E.; McCusker, J. K. J. Am. Chem. Soc. 2000, 122, 4092

(38) McCusker, J. K. Acc. Chem. Res. 2003, 36, 876.

(39) Marcus, M. A.; MacDowell, A. A.; Celestre, R.; Manceau, A.; Miller, T.; Padmore, H. A.; Sublett, R. E. J. Synchrotron Radiat. 2004, 11 , 239.

(40) Ressler, T. J. Synchrotron Radiat. 1998, 5, 118.

(41) Ankudinov, A. L.; Ravel, B.; Rehr, J. J.; Conradson, S. D. Phys. Rev. B 1998, 58, 7565 .

(42) Boillot, M. L.; Zarembowitch, J.; Itie, J. P.; Polian, A.; Bourdet, E.; Haasnoot, J. G. New J. Chem. 2002, 26, 313.

(43) Briois, V.; Sainctavit, P.; Long, G. J.; Grandjean, F. Inorg. Chem. 2001, 40,912 .

(44) Hannay, C.; HubinFranskin, M. J.; Grandjean, F.; Briois, V.; Itie, J. P.; Polian, A.; Trofimenko, S.; Long, G. J. Inorg. Chem. 1997, 36, 5580. (45) Lytle, F. W.; Greegor, R. B. Phys. Rev. B 1988, 37, 1550.

(46) Natoli, C. R.; Benfatto, M.; Doniach, S. Phys. Rev. A 1986, 34, 4682.

(47) Chen, L. X.; Wang, Z. Y.; Burdett, J. K.; Montano, P. A.; Norris, J. R. J. Phys. Chem. 1995, 99, 7958 .

(48) Lee, J. J.; Sheu, H. S.; Lee, C. R.; Chen, J. M.; Lee, J. F.; Wang,

C. C.; Huang, C. H.; Wang, Y. J. Am. Chem. Soc. 2000, 122, 5742.

(49) Erenburg, S. B.; Bausk, N. V.; Lavrenova, L. G.; Mazalov, L. N. J. Magn. Magn. Mater. 2001, 226, 1967.

(50) Okamoto, K.; Nagai, K.; Miyawaki, J.; Kondoh, H.; Ohta, T. Chem. Phys. Lett. 2003, 371, 707.

(51) Oyanagi, H.; Tayagaki, T.; Tanaka, K. J. Phys. Chem. Solids 2004, 65,1485 .

(52) Decurtins, S.; Gutlich, P.; Kohler, C. P.; Spiering, H.; Hauser, A. Chem. Phys. Lett. 1984, 105, 1.

(53) Hauser, A. Top. Curr. Chem. 2004, 234, 155. 